\title{
Clinicopathological Characteristics of Atypical Glandular Cells Determined by Cervical Cytology in Japan: Survey of Gynecologic Oncology Data from the Obstetrical Gynecological Society of Kinki District, Japan
}

\author{
Shinji Toyoda ${ }^{a}$ Ryuji Kawaguchi $^{b}$ Hiroshi Kobayashi ${ }^{b}$ \\ a Department of Obstetrics and Gynecology, Nara Prefecture General Medical Center, Nara, Japan; \\ ${ }^{\mathrm{b}}$ Department of Obstetrics and Gynecology, Nara Medical University, Kashihara, Japan
}

\section{Keywords}

Atypical glandular cells · Bethesda system · Cervical cytology · Uterus

\begin{abstract}
Background: The purpose of this study was to clarify the clinicopathological characteristics of, and the clinical approach used to identify, atypical glandular cells (AGCs) in Japan based on cervical cytology screening. Objectives: This study included 1,254 patients with AGCs who underwent cervical cytology. Method: Data from patients with AGCs were used to examine the practical management of AGCs and the histological results. Results: The incidence of AGCs was $0.20 \%(1,254 / 614,791)$. The 1,254 AGC cases included 859 endocervical cells not otherwise specified (NOS), 3 glandular cells NOS, 91 endocervical cells favor neoplasia (FN), and 301 atypical endometrial cells (AEMCs). Among the 1,254 AGC patients, the histological diagnosis was benign in $666(53.1 \%)$, cervical intraepithelial neoplasia (CIN) 1 in 60 (4.8\%), CIN2 in 31 (2.5\%), CIN3 in 52 (4.1\%), squamous cell carcinoma in $19(1.5 \%)$, adenocarcinoma in situ in 39 (3.1\%), cervical adenocarcinoma in 106 (8.5\%), endometrial carcinoma in 209 (16.7\%), ovarian cancer in 26 (2.1\%), other malig-
\end{abstract}

nancy in 4 (0.3\%), and other under follow-up in 42 (3.3\%). When the 1,254 AGC patients were divided into three medical intervention degrees according to histology, AGC-NOS, AGC-FN, and AEMC required no medical intervention in 78.7, 13.2 , and $25.9 \%(678,12$, and 78$)$ of the patients, cervical cone resection in $13.0,9.9$, and $0.3 \%(112,9$, and 1$)$ of the patients, and radical laparotomy for invasive cancer in 8.3, 76.9 , and $73.8 \%(72,70$, and 222$)$ of the patients, respectively. Conclusions: Our histological results supported the medical interventions applied for AGC diagnosis and treatment. AGC cases require careful histological evaluation.

(c) 2019 S. Karger AG, Basel

\section{Introduction}

Cervical cytology screening has considerably reduced the incidence of cervical cancer in many countries [1-3]. The risk of cervical cancer associated with abnormalities in cervical squamous cells is widely accepted [4-6], although uncertainty remains about the risk associated with abnormalities in cervical glandular cells [3]. Correspondingly, the incidence of cervical adenocarcinoma

\section{KARGER}

(c) 2019 S. Karger AG, Basel

E-Mail karger@karger.com

www.karger.com/acy
Prof. Shinji Toyoda

Department of Obstetrics and Gynecology, Nara Prefecture General Medical Center Shichijyo Nishimachi 2-897-5

Nara 6308581 (Japan)

E-Mail sjtoyoda@gmail.com 


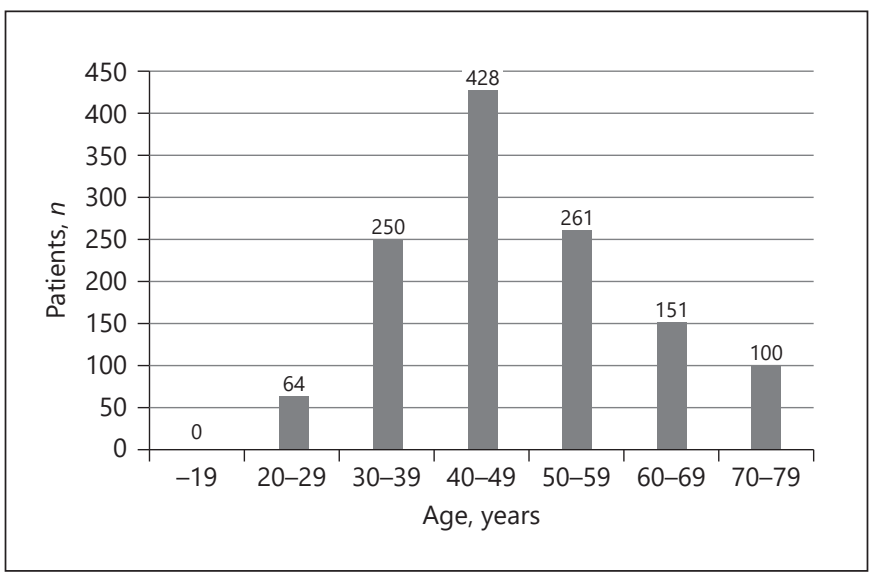

Fig. 1. Age distribution. The age distribution was as follows: 64 patients (5.1\%) were in their 20s, 250 patients (19.9\%) were in their 30 s, 428 patients $(34.1 \%)$ were in their 40 s, 261 patients $(20.8 \%)$ were in their 50s, 151 patients (12\%) were in their $60 \mathrm{~s}$, and $100 \mathrm{pa}$ tients $(8 \%)$ were in their 70 s.

has not decreased to the same extent as the incidence of cervical squamous cell cancer in many countries $[3,7,8]$.

The terminology of the field, from "atypical glandular cell of undetermined significance (AGUS)" to "atypical glandular cells" and including subcategory specifications, was defined and modified by the Bethesda system [9-11]. Atypical glandular cells (AGCs) are cytological abnormalities that are diagnosed when glandular cells exhibit changes but lack the features of adenocarcinoma in situ (AIS) or invasive adenocarcinoma of the uterine cervix. Therefore, AGCs present various histological types. Although the Bethesda system has been used globally for more than 20 years, Japanese physicians only started to utilize the system in 2008, and no evaluation of AGCs in Japan has been conducted.

The purpose of this study was to clarify the clinicopathological features of, and clinical approaches used to identify, AGCs based on cervical cytology screening in Japan.

\section{Subjects and Methods}

This study included 1,254 patients with AGCs who underwent cervical cytology screening between June 2008 and March 2017. Sixteen gynecological institutions provided their cervical cytology information. These 16 organizations were accredited by the Japanese Society of Gynecologic Oncology and the Japanese Society of Clinical Cytology. Additionally, these 16 institutions belonged to the Oncology Research Department Committee of the Obstetrical and Gynecological Society of Kinki District, Japan. The cytoprepa- ration methods used in these 16 organizations included conventional smears at 10 institutions, liquid-based cytology at 4 institutions, and both methods at 2 institutions. All clinicians followed the American Society for Colposcopy and Cervical Pathology (ASCCP) guidelines for the management of cervical cytology results [12]. Our article reports a cohort study. We obtained Ethics Review Board permission from our institution.

The present study evaluated the incidence, age distribution, subclassification, histological evaluation methods used during diagnosis, diagnostic techniques, histological results, presence of invasive cancer, degree of medical intervention, period to a definitive diagnosis, and human papillomavirus (HPV) status. As determined by the histological analysis, benign lesions included reactive changes, polyps, and standard histology.

\section{Results}

Cervical cytology data were obtained for 614,791 cases, including a total of 1,254 AGC cases. Thus, the AGC incidence rate was $0.20 \%$. The age distribution was as follows: 64 patients $(5.1 \%)$ were in their 20 s, 250 patients $(19.9 \%)$ were in their 30 s, 428 patients $(34.1 \%)$ were in their 40s, 261 patients $(20.8 \%)$ were in their 50s, 151 patients $(12 \%)$ were in their $60 \mathrm{~s}$, and 100 patients $(8 \%)$ were in their 70s (Fig. 1).

The origins of the 1,254 AGC cases included endocervical cells in 950 cases $(75.8 \%)$, glandular cells in 3 cases $(0.2 \%)$, and endometrial cells in 301 cases (24.0\%) (Fig. 2a). The subclassifications of the 1,254 AGC cases included AGCs not otherwise specified (AGC-NOS) in 862 cases (68.7\%), AGCs favor neoplasia (AGC-FN) in 91 cases $(7.3 \%)$, and atypical endometrial cells (AEMCs) in 301 cases $(24.0 \%)$ (Fig. 2 b).

The primary histological evaluation methods used during diagnosis were a colposcopic cervical biopsy in 882 cases $(70.3 \%)$, cervical canal curettage in 370 cases (29.5\%), endometrial biopsy in 511 cases (40.7\%), and direct endometrial cytology in 578 cases (46.1\%) (Fig. 3).

The diagnostic techniques used for the histological diagnosis of AGCs were a colposcopic cervical biopsy in 354 cases $(28.3 \%)$, cervical canal curettage in 155 cases (12.3\%), endometrial biopsy in 154 cases (12.3\%), cervical cone resection in 117 cases $(9.3 \%)$, radical laparotomy in 268 cases $(21.4 \%)$, repeat cervical cytology in 154 cases (12.3\%), and endometrial direct cytology alone in 10 cases $(0.8 \%)$; in addition, there was difficulty concerning the diagnosis in 42 cases (3.3\%) (Table 1 ).

The definitive diagnoses for the 1,254 AGC patients included endocervical cells NOS in 859 cases, endocervical cells FN in 91 cases, glandular cells NOS in 3 cases, and AEMCs in 301 cases. Among the 1,254 AGC patients, the 
Fig. 2. Origin and subclassifications of AGCs. a The origins of the 1,254 AGC cases included endocervical cells in 950 cases (75.8\%), glandular cells in 3 cases $(0.2 \%)$, and endometrial cells in 301 cases $(24.0 \%)$. b The subclassifications of the 1,254 AGC cases included AGC-NOS in 862 cases (68.7\%), AGC-FN in 91 cases (7.3\%), and AEMCs in 301 cases (24.0\%). AGCs, atypical glandular cells; AEMCs, atypical endometrial cells; FN, favor neoplasia; NOS, not otherwise specified.

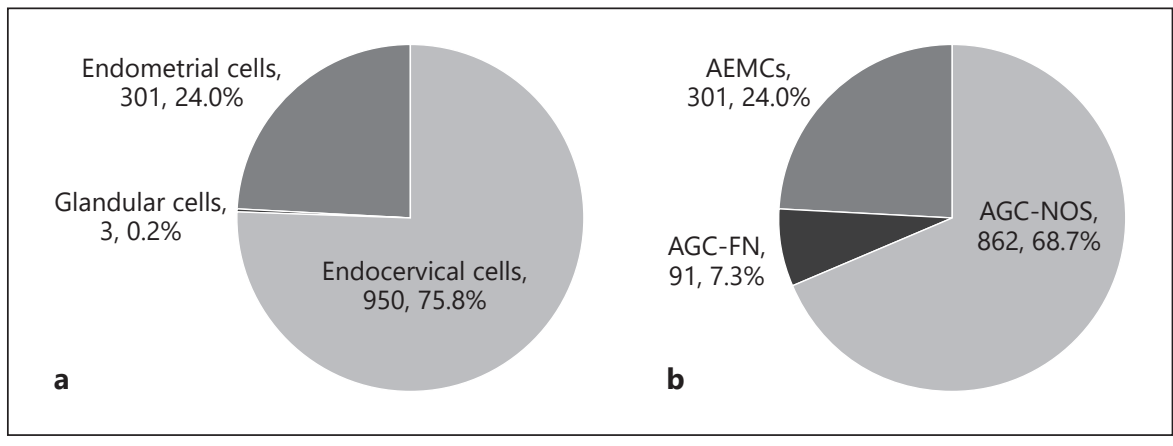

Table 1. Diagnostic techniques used for the histological diagnosis

\begin{tabular}{lc}
\hline Diagnostic technique & Patients, $n(\%)$ \\
\hline Cervical colposcopic biopsy & $354(28.3)$ \\
Cervical canal curettage & $155(12.3)$ \\
Endometrial biopsy & $154(12.3)$ \\
Conization & $117(9.3)$ \\
Radical laparotomy & $268(21.4)$ \\
Cervical cytology & $154(12.3)$ \\
Endometrial cytology & $10(0.8)$ \\
Diagnostic difficulty & $42(3.3)$ \\
\hline Total & $1,254(100)$ \\
\hline
\end{tabular}

histological diagnosis was benign in 666 (53.1\%), cervical intraepithelial neoplasia (CIN) 1 in 60 (4.8\%), CIN2 in 31 (2.5\%), CIN3 in 52 (4.1\%), squamous cell carcinoma (SCC) in $19(1.5 \%)$, AIS in 39 (3.1\%), cervical adenocarcinoma in 106 (8.5\%), endometrial carcinoma in 209 (16.7\%), ovarian cancer in $26(2.1 \%)$, other malignancy in $4(0.3 \%)$, and other under follow-up in 42 (3.3\%) (Table 2).

The definitive diagnoses for the 862 AGC-NOS patients were benign lesions in 580 patients (67.3\%), CIN1 in 58 patients $(6.7 \%), \mathrm{CIN} 2$ in 31 patients $(3.6 \%), \mathrm{CIN} 3$ in 48 patients (5.6\%), SCC in 8 patients ( $0.9 \%)$, AIS in 33 patients (3.8\%), cervical adenocarcinoma in 47 patients (5.5\%), endometrial carcinoma in 7 patients $(0.8 \%)$, ovarian cancer in 9 patients $(1.1 \%)$, other malignancy in 1 patient $(0.1 \%)$, and other under follow-up in 40 patients (4.6\%) (Table 3).

The definitive diagnoses for the 91 AGC-FN patients were benign lesions in 11 patients (12.1\%), CIN1 in 1 patient (1.1\%), CIN3 in 4 patients (4.4\%), SCC in 11 patients (12.1\%), AIS in 5 patients (5.5\%), cervical adenocarcinoma in 49 patients (53.8\%), and endometrial carcinoma in 10 patients $(11.0 \%)$ (Table 4$)$.

Clinicopathological Analysis of AGCs in Japan

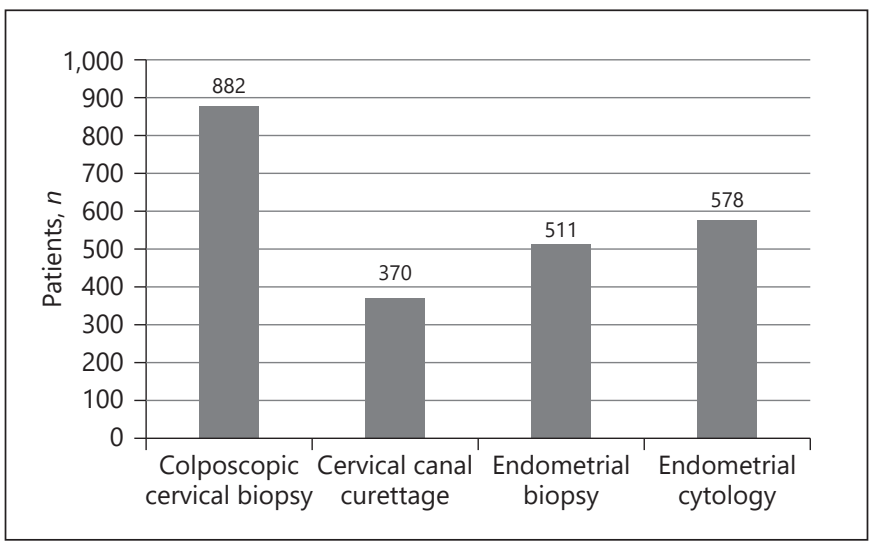

Fig. 3. Primary histological evaluation methods used during diagnosis. The histological evaluation methods were colposcopic cervical biopsy in 882 cases $(70.3 \%)$, cervical canal curettage in 370 cases $(29.5 \%)$, endometrial biopsy in 511 cases (40.7\%), and endometrial cytology in 578 cases $(46.1 \%)$.

The definitive diagnoses for the 301 AEMC patients were benign lesions in 75 patients (24.9\%), CIN1 in 1 patient $(0.3 \%)$, AIS in 1 patient $(0.3 \%)$, cervical adenocarcinoma in 10 patients $(3.3 \%)$, endometrial carcinoma in 192 patients $(63.8 \%)$, ovarian cancer in 17 patients $(5.7 \%)$, including 1 case of tubal carcinoma, other malignancy in 3 patients (1.0\%), and other under follow-up in 2 patients $(0.7 \%)$ (Table 5).

The 666 patients with benign lesions had cervical polyps in 25 cases, endometrial polyps in 9 cases, and benign endometrial hyperplasia in 24 cases.

The AGC-NOS, AGC-FN, and AEMC classifications included 72, 70, and 222 of the 364 invasive carcinomas out of the AGC cases, respectively. The 72 total cases of invasive carcinoma of the AGC-NOS category included 47 cases of cervical adenocarcinoma (12.9\%), 8 cases of SCC (2.2\%), 7 cases of endometrial carcinoma (1.9\%), 9 
Table 2. Definitive diagnoses for the 1,254 patients with AGCs

\begin{tabular}{|c|c|c|c|c|c|}
\hline \multirow[t]{3}{*}{ Histology } & \multicolumn{4}{|c|}{ Patients with AGCs $(n=1,254), n$} & \multirow[t]{3}{*}{ Total, $n(\%)$} \\
\hline & \multicolumn{2}{|c|}{ endocervical cells } & \multirow{2}{*}{$\begin{array}{l}\text { glandular cells } \\
\text { NOS }\end{array}$} & \multirow{2}{*}{ endometrial cells } & \\
\hline & NOS & FN & & & \\
\hline Benign lesions & 578 & 11 & 2 & 75 & $666(53.1)$ \\
\hline CIN1 & 58 & 1 & 0 & 1 & $60(4.8)$ \\
\hline CIN2 & 31 & 0 & 0 & 0 & $31(2.5)$ \\
\hline CIN3 & 48 & 4 & 0 & 0 & $52(4.1)$ \\
\hline SCC & 8 & 11 & 0 & 0 & $19(1.5)$ \\
\hline AIS & 33 & 5 & 0 & 1 & $39(3.1)$ \\
\hline Cervical adenocarcinoma & 47 & 49 & 0 & 10 & $106(8.5)$ \\
\hline Endometrial carcinoma & 7 & 10 & 0 & 192 & $209(16.7)$ \\
\hline Ovarian cancer & 8 & 0 & 1 & 17 & $26(2.1)$ \\
\hline Other malignancy & 1 & 0 & 0 & 3 & $4(0.3)$ \\
\hline Diagnostic difficulty & 40 & 0 & 0 & 2 & $42(3.3)$ \\
\hline Total & $859(68.5)$ & $91(7.3)$ & $3(0.2)$ & $301(24.0)$ & $1,254(100)$ \\
\hline
\end{tabular}

CIN, cervical intraepithelial neoplasia; SCC, squamous cell carcinoma; AIS, adenocarcinoma in situ; AGCs, atypical glandular cells; NOS, not otherwise specified; FN, favor neoplasia.

Table 3. Definitive diagnoses for the 862 patients with AGC-NOS

\begin{tabular}{lccc}
\hline Histology & \multicolumn{2}{l}{$\begin{array}{l}\text { Patients with AGC- } \\
\text { NOS }(n=862), n\end{array}$} & $\begin{array}{l}\text { Total, } \\
n(\%)\end{array}$ \\
\cline { 2 - 3 } & \multicolumn{2}{c}{$\begin{array}{l}\text { endocervical } \\
\text { cells }\end{array}$} & $\begin{array}{l}\text { glandular } \\
\text { cells }\end{array}$ \\
\hline Benign lesions & 578 & 2 & $580(67.3)$ \\
CIN1 & 58 & 0 & $58(6.7)$ \\
CIN2 & 31 & 0 & $31(3.6)$ \\
CIN3 & 48 & 0 & $48(5.6)$ \\
SCC & 8 & 0 & $8(0.9)$ \\
AIS & 33 & 0 & $33(3.8)$ \\
Cervical adenocarcinoma & 47 & 0 & $47(5.5)$ \\
Endometrial carcinoma & 7 & 0 & $7(0.8)$ \\
Ovarian cancer & 8 & 1 & $9(1.1)$ \\
Other malignancy & 1 & 0 & $1(0.1)$ \\
Diagnostic difficulty & 40 & 0 & $40(4.6)$ \\
\hline Total & 859 & 3 & $862(100)$ \\
\hline
\end{tabular}

CIN, cervical intraepithelial neoplasia; SCC, squamous cell carcinoma; AIS, adenocarcinoma in situ; AGCs, atypical glandular cells; NOS, not otherwise specified.

cases of ovarian cancer (2.5\%), and 1 case of other malignancy $(0.4 \%)$. The 70 cases of invasive carcinoma of the AGC-FN category included 49 cases of cervical adenocarcinoma (13.5\%), 11 cases of SCC (3.0\%), and 10 cases of endometrial carcinoma (2.7\%). The 222 invasive carcino- mas of the AEMC category included 10 cases of cervical adenocarcinoma (2.8\%), 192 cases of endometrial carcinoma (52.7\%), 17 cases of ovarian cancer $(4.7 \%)$, and 3 cases of other malignancy $(0.8 \%)$ (Table 6$)$. The subtypes in the 106 cases of cervical adenocarcinoma included endocervical adenocarcinoma usual type in 96 cases, lobular endocervical glandular hyperplasia in 4 cases, serous carcinoma in 3 cases, clear cell carcinoma in 2 cases, and endometrioid type in 1 case. The other malignancy category contained 4 cases of other malignancy (1.1\%) including 2 cases of breast cancer and 2 cases of malignant lymphoma.

According to the degree of medical intervention, the final diagnosis was divided into one of three categories: (1) no surgical intervention, (2) cervical cone resection, or (3) radical laparotomy. The "no surgical intervention" category included cases of benign lesions, those under follow-up, and CIN1. The cone resection category included cases of CIN2, CIN3, and AIS. Radical laparotomy was required for invasive carcinoma.

When we determined the required medical interventions based on histology, the 862 AGC-NOS cases resulted in nonintervention in $78.7 \%$ of the patients ( 678 cases), cervical cone resection in $13.0 \%$ of the patients (112 cases), and radical laparotomy for invasive cancer in $8.3 \%$ of the patients (72 cases). The 91 AGC-FN cases resulted in nonintervention in $13.2 \%$ of the patients ( 12 cases), cervical cone resection in $9.9 \%$ of the patients ( 9 cases), and 
Table 4. Definitive diagnoses for the 91 patients with AGC-FN

\begin{tabular}{llll}
\hline Histology & \multicolumn{2}{l}{$\begin{array}{l}\text { Patients with AGC-FN } \\
(n=91), n\end{array}$} & $\begin{array}{c}\text { Total, } \\
n(\%)\end{array}$ \\
\cline { 2 - 3 } & $\begin{array}{l}\text { endocervical } \\
\text { cells }\end{array}$ & $\begin{array}{l}\text { glandular } \\
\text { cells }\end{array}$ & \\
\hline Benign lesions & 11 & 0 & $11(12.1)$ \\
CIN1 & 1 & 0 & $1(1.1)$ \\
CIN2 & 0 & 0 & 0 \\
CIN3 & 4 & 0 & $4(4.4)$ \\
SCC & 11 & 0 & $11(12.1)$ \\
AIS & 5 & 0 & $5(5.5)$ \\
Cervical adenocarcinoma & 49 & 0 & $49(53.8)$ \\
Endometrial carcinoma & 10 & 0 & $10(11.0)$ \\
Ovarian cancer & 0 & 0 & 0 \\
Other malignancy & 0 & 0 & 0 \\
Diagnostic difficulty & 0 & 0 & 0 \\
\hline Total & 91 & 0 & $91(100)$ \\
\hline
\end{tabular}

CIN, cervical intraepithelial neoplasia; SCC, squamous cell carcinoma; AIS, adenocarcinoma in situ; AGCs, atypical glandular cells; FN, favor neoplasia.
Table 5. Definitive diagnoses for the 301 patients with AEMCs

\begin{tabular}{lc}
\hline Histology & Patients with AEMCs, $n$ (\%) \\
\hline Benign lesions & $75(24.9)$ \\
CIN1 & $1(0.3)$ \\
CIN2 & 0 \\
CIN3 & 0 \\
SCC & 0 \\
AIS & $1(0.3)$ \\
Cervical adenocarcinoma & $10(3.3)$ \\
Endometrial carcinoma & $192(63.8)$ \\
Ovarian cancer & $17(5.7)$ \\
Other malignancy & $3(1.0)$ \\
Diagnostic difficulty & $2(0.7)$ \\
\hline Total & $301(100)$ \\
\hline
\end{tabular}

AEMCs, atypical endometrial cells; CIN, cervical intraepithelial neoplasia; SCC, squamous cell carcinoma; AIS, adenocarcinoma in situ.

Table 6. Definitive diagnoses for the 364 patients with invasive carcinoma in the AGC group

\begin{tabular}{llccc}
\hline Histology & \multicolumn{2}{l}{ Patients with invasive carcinoma $(n=364), n(\%)$} & Total, $n(\%)$ \\
\cline { 2 - 4 } & $\begin{array}{l}\text { AGC-NOS } \\
(n=72)\end{array}$ & $\begin{array}{l}\text { AGC-FN } \\
(n=70)\end{array}$ & $\begin{array}{l}\text { AEMCs } \\
(n=222)\end{array}$ \\
\hline Cervical adenocarcinoma & $47(12.9)$ & $49(13.5)$ & $10(2.8)$ & $106(29.1)$ \\
SCC & $8(2.2)$ & $11(3.0)$ & 0 & $19(5.2)$ \\
Endometrial carcinoma & $7(1.9)$ & $10(2.7)$ & $192(52.7)$ & $209(57.4)$ \\
Ovarian cancer & $9(2.5)$ & 0 & $3(4.7)$ & $26(7.2)$ \\
Metastasis & $1(0.3)$ & 0 & $222(61.0)$ & $3(1.1)$ \\
\hline Total & $72(19.8)$ & $70(19.2)$ & $364(100)$ & \\
\hline
\end{tabular}

AGCs, atypical glandular cells; NOS, not otherwise specified; FN, favor neoplasia; AEMCs, atypical endometrial cells; SCC, squamous cell carcinoma.

radical laparotomy for invasive cancer in $76.9 \%$ of the patients (70 cases) (Fig. 4). The 301 AEMC cases resulted in nonintervention in $25.9 \%$ of the patients ( 78 cases), cervical cone resection in $0.3 \%$ of the patients ( 1 case), and radical laparotomy for invasive cancer in $73.8 \%$ of the patients (222 cases) (Fig. 5).

The period to definitive diagnosis from initial consultation was under 1 month for 363 cases, 1-3 months for 227 cases, 4-6 months for 69 cases, 7-12 months for 38 cases, and over 12 months for 515 cases. In all, 1,212 cas- es were evaluated; the remaining 42 cases were shown as under follow-up with diagnostic difficulty (Fig. 6).

An HPV test was performed in 73 cases, yielding 38 positive claims and 35 instances of contrary evidence (Fig. 7). The negative results of HPV testing were benign lesions in 20 cases, CIN1 in 5 cases, a cervical polyp in 2 cases, cervical adenocarcinoma usual type in 2 cases, cervical endometrioid carcinoma in 1 case, an endometrial polyp in 3 cases, and endometrial hyperplasia in 2 cases. 


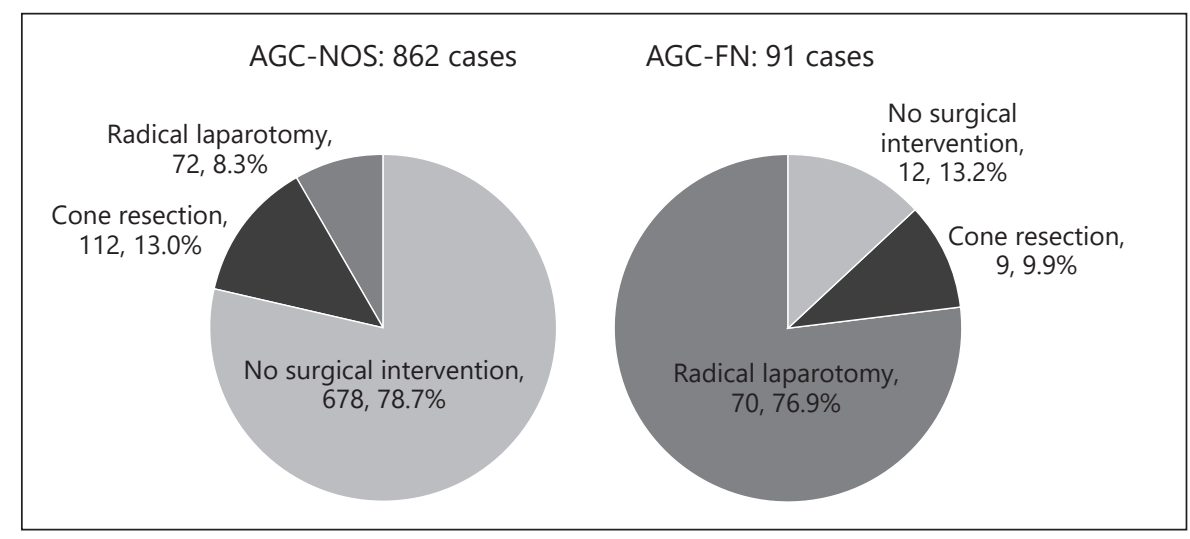

Fig. 4. Degree of medical intervention in AGC-NOS and AGC-FN. The "no surgical intervention" category included cases of benign lesions, those under follow-up, and CIN1. The cone resection category included cases of CIN2, CIN3, and AIS. Radical laparotomy was required for invasive carcinoma. When we determined the required medical interventions based on histology, the 862 AGCNOS cases resulted in nonintervention in $78.7 \%$ of the patients (678 cases), cervical cone resection in $13.0 \%$ of the patients (112

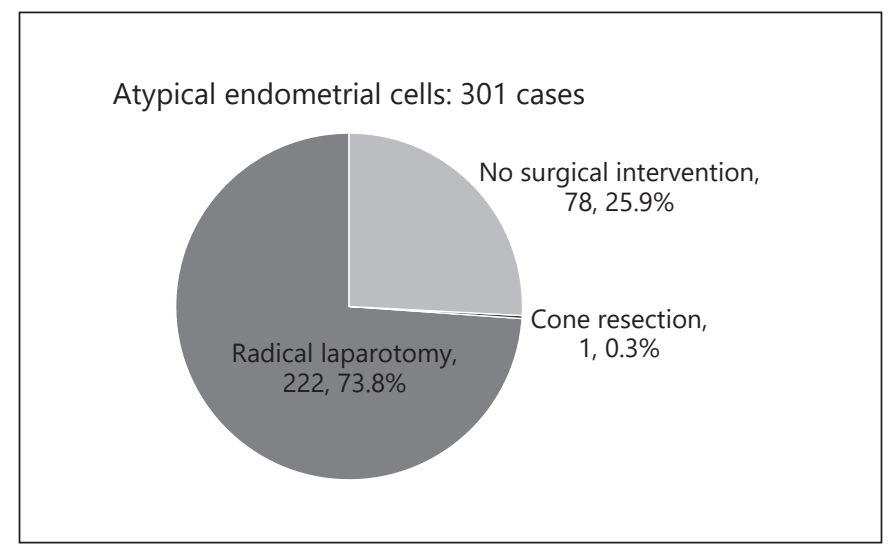

Fig. 5. Degree of medical intervention in AEMCs. The 301 AEMC cases resulted in nonintervention in $25.9 \%$ of the patients ( 78 cases), cervical cone resection in $0.3 \%$ of the patients ( 1 case), and radical laparotomy for invasive cancer in $73.8 \%$ of the patients $(222$ cases). The definitions of the categories of degrees of medical intervention are the same as in Figure 4. AEMCs, atypical endometrial cells.

\section{Discussion and Conclusion}

AGCs are cytological abnormalities diagnosed when glandular cells exhibit changes but lack the features of AIS or invasive adenocarcinoma of the uterine cervix. Clinical studies investigating the histological results for women with a diagnosis of AGCs have encompassed a broad cases), and radical laparotomy for invasive cancer in $8.3 \%$ of the patients ( 72 cases). The 91 AGC-FN cases resulted in nonintervention in $13.2 \%$ of the patients (12 cases), cervical cone resection in $9.9 \%$ of the patients ( 9 cases), and radical laparotomy for invasive cancer in $76.9 \%$ of the patients ( 70 cases). AGC, atypical glandular cell; FN, favor neoplasia; NOS, not otherwise specified; CIN, cervical intraepithelial neoplasia; AIS, adenocarcinoma in situ.

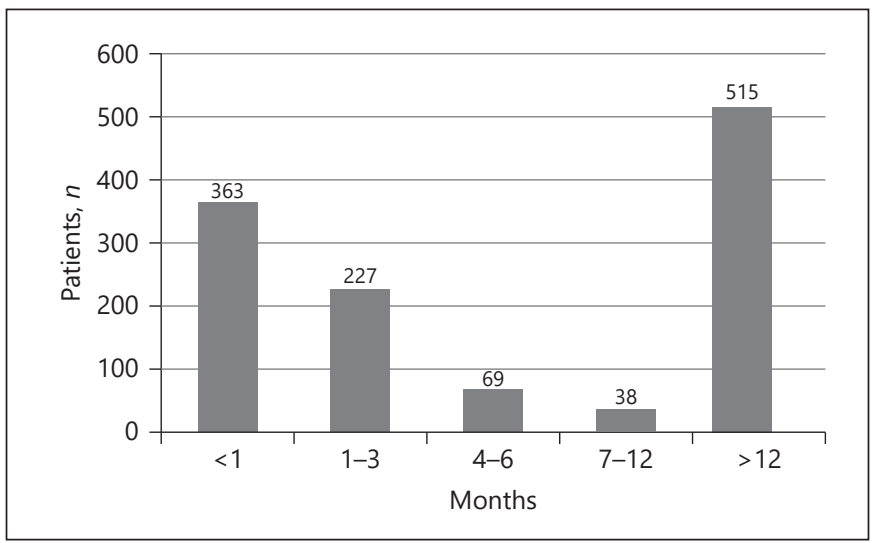

Fig. 6. Time until definitive diagnosis. The time to definitive diagnosis from initial consultation was $<1$ month in 363 cases, $1-3$ months in 227 cases, 4-6 months in 69 cases, 7-12 months in 38 cases, and $>12$ months in 515 cases. In all, 1,212 cases were evaluated; the remaining 42 cases were shown as under follow-up with diagnostic difficulty.

range of reactive changes, from mild changes and cervical precursor lesions of glandular or squamous origins to invasive cervical cancer and other gynecological cancers [13]. A previous study also demonstrated poor reproducibility between observers when interpreting AGC Pap smears [14]. In the literature, AGCs have been reported to have a $2.8-9.7 \%$ malignancy rate $[3,15,16]$. 


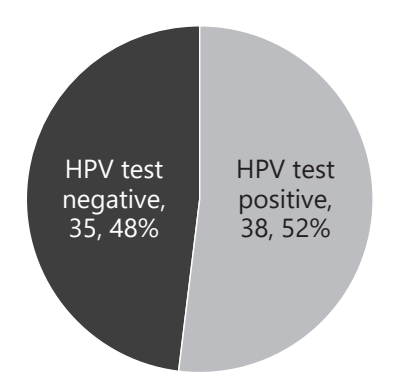

Fig. 7. HPV status. An HPV test was performed in 73 cases, yielding 38 positive claims and 35 instances of contrary evidence. HVP, human papillomavirus.

The vagueness of the AGC definition, uncertainty in the diagnosis, low incidence, minimal malignancy, multiple histological evaluation methods required, and malignant onset after an initial benign lesion are problematic for physicians. Few physicians manage persistent AGCs as recommended $[12,17,18]$. Thus, further physician education appears to be warranted [17].

The incidence of AGCs, or AGUS, has been reported to be $0.08 \%$ [19], $0.2 \%$ [20], $0.29 \%$ [13], $0.48 \%$ [3], and $5.9 \%$ [21]. Our result of $0.20 \%$ is not significantly different from these reported rates. Our data showed that 428 patients were in their 40s, 261 were in their 50s, and 250 were in their 30s. This age distribution did not reveal any striking characteristics. However, in one recent report, Wang et al. [3] described a higher risk of cervical cancer among women with AGCs aged $30-39$ years and that this increased risk was primarily derived from an increased risk of adenocarcinoma. Therefore, the 30s might be an essential age range for follow-up. When organized by subclassification, AGC-FN comprised 7.3\% of the 1,254 total AGC cases, which was consistent with recent reports showing rates of $14.7-34.5 \%$ [22-25]. The reason for the low occurrence of AGC-FN was that the AEMC ratio was high in AGCs, but further details were unknown.

In a comprehensive evaluation of women with cytological AGCs, various techniques were applied, including pelvic examination, ultrasonography, colposcopy, endocervical curettage, cervical biopsy, and endometrial biopsy $[3,13,26,27]$. Cervical biopsy and endometrial sampling are the principal early tests [12]. The detection rates of abnormal lesions reported by Kim et al. [19] were 3.1\% with repeated Pap smears, $28.4 \%$ with colposcopy-directed biopsy, $63.6 \%$ with cone biopsy, and $29.7 \%$ with endo-

Clinicopathological Analysis of AGCs in Japan metrial curettage. The authors recommend that patients with AGUS by Pap smear undergo immediate intensive diagnostic assessment, including colposcopy-directed biopsy with endocervical curettage or cone biopsy, to detect cervical lesions and endometrial curettage to detect endometrial lesions. In our study, the canal curettage rate was meager compared with the rate in the data collected by Kim et al. [19]. This low canal curettage rate might be due to lack of recognition of the hidden and latent malignant tendency of AGCs by Japanese gynecological physicians. Moreover, $13.1 \%$ of the diagnostic techniques, including cervical and endometrial cytology alone, showed little diagnostic ability for AGCs. Importantly, various types of procedure, including endometrial cytology, are needed to evaluate the endometrial sample for AGCs.

Schnatz et al. [13] reported that 6,829 AGUC cases explained $71.0 \%$ of benign findings including reactive changes, polyps, and normal histology, $8.5 \%$ of low-grade squamous intraepithelial lesions (LSILs), $11.1 \%$ of highgrade squamous intraepithelial lesions (HSILs), 2.9\% of AIS, and $5.2 \%$ of malignancies. Our AGC-NOS data showed $67.3 \%$ benign findings, $6.7 \%$ LSILs (CIN1), 9.2\% HSILs (including $6.7 \%$ of CIN2 and $3.6 \%$ of CIN3), $3.8 \%$ AIS, and $8.4 \%$ malignancies (Table 3 ). Our study found high rates of HSIL, AIS, and malignancy but low rates of benign findings and LSIL compared with those found by Schnatz et al. [13]. However, neither their nor our study recognized a significant difference in histology. Therefore, our AGC-NOS data demonstrated that many benign lesions were included. There was another report that invasive cancer did not occur in 91 AGC-NOS cases [28], whereas we showed a frequency of $8.4 \%$. The reason why our rate of malignancy was high was not apparent, but an improvement in accuracy of the cytological diagnosis might be required. Our data showed that $12.1 \%$ of the AGC-FN cases were benign, $1.1 \%$ were LSILs (CIN1), $4.4 \%$ were HSILs (CIN3), $5.5 \%$ were AIS, $53.8 \%$ were cervical adenocarcinomas, and $11.0 \%$ were endometrial carcinomas (Table 4). AIS and cervical adenocarcinoma accounted for $59.3 \%$ of the total AGC-FN cases. Therefore, the AGC-FN data demonstrated that many cervical glandular lesions were included. Glandular neoplasia had a frequency of $27 \%$ in a report on 15 AGC-FN cases [28], whereas our data showed a high frequency of $59.3 \%$. As with the cases of AGS-NOS, we might need more careful control of the cytological accuracy for AGC-FN. Our data showed that $24.9 \%$ of the AEMC cases were benign, $0.3 \%$ were LSILs (CIN1), $0.3 \%$ were AIS, 3.3\% were cervical adenocarcinomas, $63.8 \%$ were endometrial carcinomas, $5.7 \%$ were ovarian cancer, and $1.0 \%$ were some other ma- 
lignancy (Table 5). Therefore, the AEMC data demonstrated that many endometrial carcinomas were included. In summary, AGC-NOS encompasses numerous benign lesions and a few cervical glandular lesions, AGC-FN encompasses many cervical glandular malignancies, and AEMCs encompass a large number of endometrial cancers. Therefore, a clear distinction between these three groups is required for clinical management.

The reported rates of dysplasia and malignancy that are associated with AGCs vary widely and range from 17 to $59 \%[15,20,21,29]$. A total of 364 malignancies accounted for $29.0 \%$ of the AGC cases in this study. We examined malignancies divided into AGC-NOS, AGC-FN, and AEMCs. Out of the 72 cases of malignancy in the AGC-NOS group, 47 (65.3\%) were diagnosed as cervical adenocarcinoma, 8 (11.1\%) were diagnosed as SCC, 7 (9.7\%) were diagnosed as endometrial carcinoma, 9 (12.5\%) were diagnosed as ovarian cancer, and 1 (1.4\%) was diagnosed as some other malignancy. Out of the 70 cases of malignancy in the AGC-FN group, 49 (70.0\%) were diagnosed as cervical adenocarcinoma, 11 (15.7\%) were diagnosed as SCC, and 7 (9.7\%) were diagnosed as endometrial carcinoma. Out of the 222 AEMC cases, 10 (65.3\%) were diagnosed as cervical adenocarcinoma, 192 (57.4\%) were diagnosed as endometrial carcinoma, 17 $(4.7 \%)$ were diagnosed as ovarian cancer, and $3(1.1 \%)$ were diagnosed as another malignancy. In summary, in the subclasses, malignant cervical lesions were characteristic among the cases of AGC-NOS and AGC-FN, and endometrial carcinoma was distinctive among AEMCs.

When the AGC cases were divided into three medical intervention degrees according to histology, AGC-NOS required radical laparotomy for invasive cancer in $8.3 \%$ of the cases, cervical cone resection in $13.0 \%$ of the cases, and nonintervention in $78.7 \%$ of the cases. AGC-FN required radical laparotomy for invasive cancer in $76.9 \%$ of the cases, cervical cone resection in $9.9 \%$ of the cases, and nonintervention in $13.2 \%$ of the cases. AEMCs required radical laparotomy for invasive cancer in $73.8 \%$ of the cases, cervical cone resection in $0.3 \%$ of the cases, and nonintervention in $25.9 \%$ of the cases. These results supported the clinical approach applied for AGCs in Japan. This study is the first report of a simplified management rate for AGCs.

Gynecological malignancies comprise $16-84 \%$ of invasive cervical cancers, $4-77 \%$ of uterine cancers, and $4-8 \%$ of ovarian cancers $[13,20,26,30]$. For endometrial cancer, Liao et al. [31] and Lee et al. [14] reported that the rate of endometrial cancer was up to 10\% in AGC cases. Our data including AGC-NOS and AGC-FN showed an endometrial cancer rate of $1.8 \%$ among the patients (17/953). In contrast, AEMCs showed an endometrial cancer rate of $63.8 \%$. Clinically, AEMCs should be instrumental in the detection of endometrial lesions. So as not to misunderstand that endometrial cancer is determined by cervical sampling, we chose endometrial cytology or endometrial biopsy when endometrial malignancies were suspected.

We focused on results related to initial testing for AGCs in this study. Cheng et al. [26] reported that AGC cases had an approximately 18 -fold higher incidence of cervical cancer, a 6-fold higher incidence of uterine cancer, and a 2 -fold higher incidence of ovarian cancer than the general screening population. Women with AGCs found at screening should immediately be adequately assessed by histological analysis and must not be lost to follow-up [3]. Therefore, an intent approach to histological analysis at the initial visit is critical $[15,19]$. Our study focused on histology at the initial visit and showed a rate of early diagnosis ( $<4$ months) of only $47.0 \%$ (590/1,254 cases), which might indicate that early diagnosis of AGCs is difficult.

A total of 622 cases (49.6\%) from our data received a diagnosis more than 3 months after initial testing. In these 622 cases, the difficulty in differentiating false negatives from a newly originated lesion during follow-up limited our study. In the literature, the false negative rate was $4.7 \%$ in initial testing [18], and 12 of 42 AGC cases (29\%) were diagnosed more than 1 year after the initial AGUS Pap test [18]. A missed or ineffectively eliminated glandular lesion during or after the initial histological identification of AGCs would not be as visible and accessible as squamous lesions using colposcopic methods [3, 32-34]. Therefore, follow-up testing is also significant [3, 19]. A recent practical suggestion for follow-up is a more aggressive assessment strategy, such as including an additional histological analysis at 1 year and close surveillance for many years [3]. A cytology result of AGCs may require long-term management for final histology.

High-risk HPV DNA is found in $9.0-34.0 \%$ of AGC cases $[16,24,35]$. HPV testing may improve prediction of the risk of cancer after detection of AGCs, because cervical adenocarcinoma and its precursor lesions are also related to HPV infection $[3,24,36]$. In 2006, consensus guidelines for managing AGCs released by the ASCCP included high-risk HPV testing for women with AGCpositive Pap test results $[11,16]$. In our analysis, 38 cases included an HPV test with a positive result and 35 included an HPV test with contrary findings. This low number of submitted HPV-tested AGC cases came about because health insurance did not approve HPV testing for AGC cases in Japan. In addition to the small number of cases, HPV typing was not considered in this paper. Al- 
though endocervical adenocarcinomas of the usual type are etiologically related to infection with oncogenic HPVs [37], rarer endocervical adenocarcinoma subtypes, i.e., clear cell, serous, endometrioid, and gastric type, showed much lower rates in relation with HPV [38]. These reports suggested that special attention should be given to specific rarer endocervical adenocarcinoma subtypes, as most appear to be unrelated to HPV $[37,38]$. In this article, $1 \mathrm{HPV}$-negative case in AGCs was an endometrioidtype endocervical adenocarcinoma. By increasing the number of cases, we must pay close attention to the histological diagnosis of HPV-negative cases in AGCs. The incorporation of HPV testing in AGC smears for clarification might be an important strategy in Japan.

This study has two limitations. The first limitation is that although in many cases, histological results were received after 1 year or more, this study did not provide any diagnostic interval description of the period. Therefore, an examination of the appropriate interval of visits for patients with AGCs should be performed in the future. The second limitation is that there were 42 follow-up cases of diagnostic difficulty, which may have affected frequencies of histological types that may be determined in the future.

In conclusion, our data show the necessity of using various techniques for the histological analysis of AGCs, and our histological results support the medical intervention provided. This study is the first to evaluate a large number of AGC patients in Japan. However, unanswered questions remain concerning histology in follow-up cases.

\section{Acknowledgements}

We gratefully thank many medical doctors in the Kinki District of Japan: Tomoyuki Ichimura and Toshiyuki Sumi (Department of Obstetrics and Gynecology, Osaka City University), Hiroyuki
Fujita (Department of Obstetrics and Gynecology, Japanese Red Cross Kyoto Daini Hospital), Motonori Matsubara and Kiyoshi Fujiwara (Department of Obstetrics and Gynecology, Tenri Hospital), Gen Honjo (Department of Pathology, Tenri Hospital), Nobutaka Hayashi and Shinya Yoshioka (Department of Obstetrics and Gynecology, Kobe City Medical Center General Hospital), Toshitada Ogasawara (Department of Obstetrics and Gynecology, Okubo Hospital), Ai Miyoshi and Takeshi Yokoi (Department of Obstetrics and Gynecology, Kaizuka City Hospital), Masato Miyama (Department of Gynecology, Izumi Municipal Hospital), Masanori Kanemura (Department of Obstetrics and Gynecology, National Hospital Organization Osaka Minami Medical Center), Masahiko Takemura (Department of Obstetrics and Gynecology, Osaka General Medical Center), Shouko Idemoto and Naoki Kawamura (Department of Gynecology, Osaka City General Hospital), Ken Inoue (Department of Pathology, Osaka City General Hospital), Atsuko Taga and Yukiyasu Sato (Department of Obstetrics and Gynecology, Japanese Red Cross Otsu Hospital), Tsunekazu Kita (Department of Obstetrics and Gynecology, Nara Prefecture General Medical Hospital), Tsukuru Amano and Takashi Murakami (Department of Obstetrics and Gynecology, Shiga University of Medical Science Hospital), Sumire Sugimoto (Department of Obstetrics and Gynecology, Nara Medical University), Yasushi Mabuchi and Kazuhiki Ino (Department of Obstetrics and Gynecology, Wakayama Medical University Hospital), Yasuhiko Ebina and Hideto Yamada (Department of Obstetrics and Gynecology, Kobe University Graduate School of Medicine), Takehiro Kido and Hidetaka Okada (Department of Obstetrics and Gynecology, Kansai Medical University Hospital), and Norie Tanaka and Tadashi Kimura (Department of Obstetrics and Gynecology, Osaka University Hospital).

\section{Statement of Ethics}

The authors have no ethical conflicts to disclose.

\section{Disclosure Statement}

The authors have no conflicts of interest to declare.

\section{References}

1 Macgregor JE, Campbell MK, Mann EM, Swanson KY. Screening for cervical intraepithelial neoplasia in north east Scotland shows fall in incidence and mortality from invasive cancer with concomitant rise in preinvasive disease. BMJ. 1994 May;308(6941):1407-11.

2 Thun MJ, DeLancey JO, Center MM, Jemal A, Ward EM. The global burden of cancer: priorities for prevention. Carcinogenesis. 2010 Jan;31(1):100-10.
3 Wang J, Andrae B, Sundström K, Ström P, Ploner A, Elfström KM, et al. Risk of invasive cervical cancer after atypical glandular cells in cervical screening: nationwide cohort study. BMJ. 2016 Feb;352:i276.

4 McCredie MR, Sharples KJ, Paul C, Baranyai J, Medley G, Jones RW, et al. Natural history of cervical neoplasia and risk of invasive cancer in women with cervical intraepithelial neoplasia 3: a retrospective cohort study. Lancet Oncol. 2008 May;9(5):425-34.

5 Ostör AG. Natural history of cervical intraepithelial neoplasia: a critical review. Int J Gynecol Pathol. 1993 Apr;12(2):186-92.
6 Gustafsson L, Adami HO. Natural history of cervical neoplasia: consistent results obtained by an identification technique. $\mathrm{Br} \mathrm{J}$ Cancer. 1989 Jul;60(1):132-41.

7 Bray F, Carstensen B, Møller H, Zappa M, Zakelj MP, Lawrence G, et al. Incidence trends of adenocarcinoma of the cervix in 13 European countries. Cancer Epidemiol Biomarkers Prev. 2005 Sep;14(9):2191-9. 
8 Smith HO, Tiffany MF, Qualls CR, Key CR. The rising incidence of adenocarcinoma relative to squamous cell carcinoma of the uterine cervix in the United States - a 24-year population-based study. Gynecol Oncol. 2000 Aug; 78(2):97-105.

9 Solomon D, Davey D, Kurman R, Moriarty A, O’Connor D, Prey M, et al.; Bethesda 2001 Workshop. The 2001 Bethesda System: terminology for reporting results of cervical cytology. JAMA. 2002 Apr;287(16):2114-9.

10 Broder S. From the National Institutes of Health. JAMA. 1992 Apr;267(14):1892.

11 Soloman D. The 1988 Bethesda System for reporting cervical/vaginal cytologic diagnoses: developed and approved at the National Cancer Institute workshop in Bethesda, MD, December 12-13, 1988. Diagn Cytopathol. 1989; 5(3):331-4.

12 Wright TC Jr, Massad LS, Dunton CJ, Spitzer M, Wilkinson EJ, Solomon D; 2006 American Society for Colposcopy and Cervical Pathology-Sponsored Consensus Conference. 2006 consensus guidelines for the management of women with abnormal cervical cancer screening tests. Am J Obstet Gynecol. 2007 Oct; 197(4):346-55.

13 Schnatz PF, Guile M, O'Sullivan DM, Sorosky JI. Clinical significance of atypical glandular cells on cervical cytology. Obstet Gynecol. 2006 Mar;107(3):701-8.

14 Lee KR, Darragh TM, Joste NE, Krane JF, Sherman ME, Hurley LB, et al. Atypical glandular cells of undetermined significance (AGUS): interobserver reproducibility in cervical smears and corresponding thin-layer preparations. Am J Clin Pathol. 2002 Jan; 117(1):96-102.

15 Meath AJ, Carley ME, Wilson TO. Atypical glandular cells of undetermined significance. Review of final histologic diagnoses. J Reprod Med. 2002 Apr;47(4):249-52.

16 Namugenyi SB, Balsan MJ, Glick SN, Jordan JA. Prevalence and genotype distribution of human papillomavirus in cytology specimens containing atypical glandular cells: a casecontrol study. J Clin Virol. 2013 Oct;58(2): 432-6.

17 Smith-McCune K, Mancuso V, Contant T, Jackson R. Management of women with atypical Papanicolaou tests of undetermined significance by board-certified gynecologists: discrepancies with published guidelines. Am J Obstet Gynecol. 2001 Sep;185(3):551-6.

18 Sharpless KE, Schnatz PF, Mandavilli S, Greene JF, Sorosky JI. Lack of adherence to practice guidelines for women with atypical glandular cells on cervical cytology. Obstet Gynecol. 2005 Mar;105(3):501-6.
19 Kim TJ, Kim HS, Park CT, Park IS, Hong SR, Park JS, et al. Clinical evaluation of follow-up methods and results of atypical glandular cells of undetermined significance (AGUS) detected on cervicovaginal Pap smears. Gynecol Oncol. 1999 May;73(2):292-8.

20 Kennedy AW, Salmieri SS, Wirth SL, Biscotti CV, Tuason LJ, Travarca MJ. Results of the clinical evaluation of atypical glandular cells of undetermined significance (AGCUS) detected on cervical cytology screening. Gynecol Oncol. 1996 Oct;63(1):14-8.

21 Geier CS, Wilson M, Creasman W. Clinical evaluation of atypical glandular cells of undetermined significance. Am J Obstet Gynecol. 2001 Jan;184(2):64-9.

22 Sawangsang P, Sae-Teng C, Suprasert P, Srisomboon J, Khunamornpong S, Kietpeerakool C. Clinical significance of atypical glandular cells on Pap smears: experience from a region with a high incidence of cervical cancer. J Obstet Gynaecol Res. 2011 Jun;37(6): 496-500.

23 Shoji T, Takatori E, Takeuchi S, Yoshizaki A, Uesugi N, Sugai T, et al. Clinical significance of atypical glandular cells in the Bethesda system 2001: a comparison with the histopathological diagnosis of surgically resected specimens. Cancer Invest. 2014 May;32(4):105-9.

24 Zeferino LC, Rabelo-Santos SH, Villa LL, Sarian LO, Costa MC, do Amaral Westin MC, et al. Value of HPV-DNA test in women with cytological diagnosis of atypical glandular cells (AGC). Eur J Obstet Gynecol Reprod Biol. 2011 Nov;159(1):160-4.

25 Chatchotikawong U, Ruengkhachorn I, Laiwejpithaya S. Factors predicting pathologic significance among women with atypical glandular cells on liquid-based cytology. Int J Gynaecol Obstet. 2012 Oct;119(1):30-4.

26 Cheng WF, Chen YL, You SL, Chen CJ, Chen YC, Hsieh CY, et al. Risk of gynaecological malignancies in cytologically atypical glandular cells: follow-up study of a nationwide screening population. BJOG. 2011 Jan;118(1): 34-41.

27 Solomon D, Frable WJ, Vooijs GP, Wilbur DC, Amma NS, Collins RJ, et al. ASCUS and AGUS criteria. International Academy of $\mathrm{Cy}$ tology Task Force summary. Diagnostic $\mathrm{Cy}$ tology Towards the 21st Century: An International Expert Conference and Tutorial. Acta Cytol. 1998 Jan-Feb;42(1):16-24.

28 Westin MC, Derchain SF, Rabelo-Santos SH, Angelo-Andrade LA, Sarian LO, Oliveira E, et al. Atypical glandular cells and adenocarcinoma in situ according to the Bethesda 2001 classification: cytohistological correlation and clinical implications. Eur J Obstet Gynecol Reprod Biol. 2008 Jul;139(1):79-85.
29 Burja IT, Thompson SK, Sawyer WL Jr, Shurbaji MS. Atypical glandular cells of undetermined significance on cervical smears. A study with cytohistologic correlation. Acta Cytol. 1999 May-Jun;43(3):351-6.

30 Zhao C, Florea A, Onisko A, Austin RM. Histologic follow-up results in 662 patients with Pap test findings of atypical glandular cells: results from a large academic womens hospital laboratory employing sensitive screening methods. Gynecol Oncol. 2009 Sep;114(3): 383-9.

31 Liao SY, Rodgers WH, Kauderer J, Bonfiglio TA, Darcy KM, Carter R, et al. Carbonic anhydrase IX (CA-IX) and high-risk human papillomavirus (H-HPV) as diagnostic biomarkers of cervical dysplasia/neoplasia in Japanese women with a cytologic diagnosis of atypical glandular cells (AGC): a Gynecologic Oncology Group (GOG) Study. Br J Cancer. 2011 Jan;104(2):353-60.

32 Costales AB, Milbourne AM, Rhodes HE, Munsell MF, Wallbillich JJ, Brown J, et al. Risk of residual disease and invasive carcino$\mathrm{ma}$ in women treated for adenocarcinoma in situ of the cervix. Gynecol Oncol. 2013 Jun; 129(3):513-6.

33 Kennedy AW, Biscotti CV. Further study of the management of cervical adenocarcinoma in situ. Gynecol Oncol. 2002 Sep;86(3):361-4.

34 Widrich T, Kennedy AW, Myers TM, Hart WR, Wirth S. Adenocarcinoma in situ of the uterine cervix: management and outcome. Gynecol Oncol. 1996 Jun;61(3):304-8.

35 Katki HA, Schiffman M, Castle PE, Fetterman B, Poitras NE, Lorey T, et al. Five-year risks of CIN $3+$ and cervical cancer among women with HPV-positive and HPV-negative highgrade Pap results. J Low Genit Tract Dis. 2013 Apr;17(5 Suppl 1):S50-5.

36 Ronco G, Dillner J, Elfström KM, Tunesi S, Snijders PJ, Arbyn M, et al.; International HPV screening working group. Efficacy of HPV-based screening for prevention of invasive cervical cancer: follow-up of four European randomised controlled trials. Lancet. 2014 Feb;383(9916):524-32.

37 Park KJ, Kiyokawa T, Soslow RA, Lamb CA, Oliva E, Zivanovic $\mathrm{O}$, et al. Unusual endocervical adenocarcinomas: an immunohistochemical analysis with molecular detection of human papillomavirus. Am J Surg Pathol. 2011 May;35(5):633-46.

38 Holl K, Nowakowski AM, Powell N, McCluggage WG, Pirog EC, Collas De Souza S, et al. Human papillomavirus prevalence and typedistribution in cervical glandular neoplasias: results from a European multinational epidemiological study. Int J Cancer. 2015 Dec; 137(12):2858-68. 